Southampton W/HS

University Hospitals NHS Trust

\title{
The CHildren's INterval Appendicectomy (CHINA) study
}

\section{A Prospective Randomised Evaluation of Interval Appendicectomy versus Conservative Follow-Up Following Successful Non-Operative Treatment of Appendix Mass in Children}

\section{PARENTS INFORMATION SHEET}

We are asking you and your child to take part in a research project. Before you decide it is important that you understand why the research is being done and what it will mean for you and your child. You should discuss this with your doctor. Please ask us if there is anything else that is not clear or you would like to know.

\section{Why are we doing this research?}

Your child has recently been treated in hospital for a type of appendicitis called an appendix mass. We know from experience that the best way to treat children with this type of appendicitis is with antibiotics alone in the first instance. However we do not know the best way to treat children once they have got better. Some doctors think that everyone should have their appendix taken out in a few months time to stop them getting appendicitis again but other doctors think that this is not necessary as not all children will actually get appendicitis again. We are doing this research to determine whether it is necessary to take the appendix out, at a later stage, in children such as yours.

\section{What will happen to my child if we do take part?}

If you agree to take part in the study we will ask a computer to decide at random whether your child will have his/her appendix taken out or not. This is a bit like tossing a coin.

If it decides that your child will have his/her appendix out then we will get you back in a few months time for an operation to take the appendix out. Your child will come into hospital for a few days and have an operation to remove the appendix. The operation is generally very safe. He/she will require some time off school or normal daily activities after this.

If it decides that your child will not have his/her appendix taken out then we will arrange for you and your child to visit our outpatient clinic several times during the next year so that we can check up on him/her.

\section{What are the risks?}

It is important that you and your child understand the risks of each of these options. The main risk of having an operation to remove the appendix is that your child may be having an operation that he/she does not actually need. We think that 4 out of every 5 children do not need the operation. The main risk of not having the operation is that your child might get appendicitis again. If this happens he/she would need treating in hospital, much like he/she has been recently and may then have an operation to remove the appendix. We think that this happens to only 1 in every 5 children. In addition there is a very small risk (less than 1 in 100) of there being an underlying condition affecting the appendix. Having such a condition is unlikely to have any long term implications but it may increase slightly the risk of getting appendicitis again. 


\section{Do I have to take part?}

No, taking part is up to you and your child. If you decide not to take part you do not have to give a reason and no one will be upset. Your child's treatment will not be affected if you do not take part.

\section{What are the potential benefits of taking part?}

This study will not bring any immediate benefit to your child. After we have finished the study we can let you know the results if you would like to know. We hope that we will get information about how best to treat children such as yours in the future.

\section{Who will know that I am taking part in the study?}

All the information we keep about your child will be kept confidential. This means that we will only tell those people who need to know. With your permission we will let your GP know that you are taking part in this study.

\section{What are the arrangements for compensation?}

This research has been approved by the Isle of Wight, Portsmouth and South East Hampshire Research Ethics Committee. This is an independent committee who believe that the study is of minimal risk to your child. However, research can carry unforeseen risk and we want you to be informed of your rights on the unlikely event that any harm should occur as a result of taking part in this study.

No special compensation arrangements have been made for this project but you have the right to claim damages in a court of law. This will require you to prove fault on the part of the Hospital treating your child.

\section{Details on how to contact the researchers.}

If you would like to contact the researchers you may do so through the consultant in charge of your child's care or the study co-ordinator in writing. The overall research study is being co-ordinated by:

\section{Mr Nigel Hall}

Clinical Lecturer

Department of Paediatric Surgery

Mailpoint 44

Southampton General Hospital

Tremona Road

Southampton SO16 6YD

Tel: 02380794144

E-mail: n.hall@suht.swest.nhs.uk

\author{
Mr David Burge \\ Consultant Paediatric Surgeon \\ Department of Paediatric Surgery \\ Mailpoint 44 \\ Southampton General Hospital \\ Tremona Road \\ Southampton SO16 6YD \\ Tel: 02380796677 \\ E-mail: david.burge@suht.swest.nhs.uk
}

